\title{
Otel-Restoran Kredileri ile BIST Turizm Endeksinin Psikolojik ve Ekonomik Yansımaları: Türkiye Örneği
}

\author{
Psychological and Economic Aspects of BIST Tourism Index with Hotel- \\ Restaurant Credits: Turkey Example
}

Filiz YETiZ ${ }^{1} \odot$, Aynur SÜSAY² $\odot$, Ayşe ERGIN ÜNAL ${ }^{3} \odot$

\section{öz}

Türkiye' de genel itibari ile hizmetler sektörü özelde ise alt hizmet sektörleri arasında yer alan turizm sektörünün Gayrisafi yurtiçi hasıladaki payı gittikçe artmaktadır. Dünya hizmet ticareti perspektifinden bakıldığında ise neredeyse yüzde 30 dolaylarında ağırlığı olan sektörün ülke ekonomilerine katkısı yadsınamaz boyuttadır. Ekonomideki öneminden dolayı bankalar turizm sektörünün gelişmesine yönelik uygun fiyat, vade ve limit seçenekleri ile çeşitli işletme ve yatırım kredileri sağlamakta sektörün ihtiyacına yönelik yeni kredi destek paketleri oluşturmaktadır. Bankacılık sistemi turizm sektöründe faaliyetlerin sürdürülmesi, yeni turizm işletmelerin kurulması, işletmelerin yenilemesi, tadilat faaliyetlerinin desteklenmesi amacıyla sektöre çeşitli kredi ürünleriyle sürekli destek olmaktadır.

Bu bağlamda çalışmanın amacı Türkiye' de turizm sektörünü etkileyen psikolojik ve ekonomik çeşitli büyüklükler arasındaki nedensellik ilişkisini tespit etmek olup çalışmada 2011:01-2021:02 dönemi aylık verileri ve Toda Yamamoto Nedensellik testi kullanılmıştır. Çalışmada bankacılık sisteminin finanse ettiği toplam turizm kredileri ile BIST turizm endeksinin psikolojik ve ekonomik etkilerinin araştırılmasında 6 farklı değişken tercih edilmiştir. Değişkenler arasında yer alan Sanayi Üretim Endeksi, BIST Turizm Endeksi, Otel ve Restoranlar (Turizm) Toplam Nakdi Kredileri, TÜFE Göstergeleri (Lokanta ve Oteller) sektördeki ekonomik yansımaları temsil ederken Hizmet Sektörü Güven Endeksi ve Türkiye Jeopolitik Risk Endeksi psikolojik etkileri temsil etmektedir. Yapılan nedensellik testi sonucuna göre Hizmet Sektörü Güven Endeksinden büyümeye ve TÜFE göstergelerine, BIST Turizm Endeksinden Hizmet Sektörü Güven Endeksi'ne doğru tek yönlü nedensellik ilişkisi elde edilmiştir. Otel ve Restoranlar (Turizm) Toplam Nakdi Kredilerinden TÜFE'ye doğru tek yönlü nedensellik ilişkisi ise diğer bulgular arasındadır.

Anahtar Kelimeler: Hizmet sektörü güven endeksi, Türkiye jeopolitik risk endeksi, Otel ve restoranlar, Toplam nakdi kredileri, TÜFE, BIST turizm endeksi

Jel Sınıflaması: A10, Z30, Z33

\section{DOI: 10.26650/JEPR926459}

'Doç. Dr., Akdeniz Üniversitesi, Uygulamalı Bilimler Fakültesi, Finans ve Bankacılık Bölümü, Antalya, Türkiye

${ }^{2}$ Araştırma Görevlisi, Tarsus Üniversitesi, Uygulamalı Bilimler Fakültesi, Finans ve Bankacılık Bölümü, Mersin, Türkiye ${ }^{3}$ Doç. Dr., Tarsus Üniversitesi, Uygulamalı Bilimler Fakültesi, Finans ve Bankacılık Anabilim Dalı, , Mersin, Türkiye

ORCID: F.Y. 0000-0001-5480-9268;

A.S. 0000-0003-0935-7375;

A.E.Ü. 0000-0001-6551-8933;

\section{Sorumlu yazar/Corresponding author:}

Filiz YETiZ,

Akdeniz Üniversitesi, Uygulamalı Bilimler Fakültesi, Finans ve Bankacilık Bölümü, Antalya, Türkiye

E-posta/E-mail:

filiz.yetiz@gmail.com

Başvuru/Submitted: 22.04 .2021

Revizyon Talebi/Revision Requested:

12.07.2021

Son Revizyon/Last Revision Received: 20.07.2021

Kabul/Accepted: 27.11.2021

Atıf/Citation: Yetiz, F., Susay, A., \& Ergin Unal, A. (2022). Otel-restoran kredileri ile BIST turizm endeksinin psikolojik ve ekonomik yansımaları: Türkiye örneği. Iktisat Politikası Araştırmaları Dergisi - Journal of Economic Policy Researches, 9(1), 187-204.

https://doi.org/10.26650/JEPR926459 


\begin{abstract}
In gross domestic product the share of the tourism sector, which is among the sub-service sectors in Turkey in general and the services sector in particular, is increasing gradually. From the perspective of the world service trade, the contribution of the sector, which weighs almost 30\%, to the country's economies is undeniable. Considering its importance in the economy, banks provide affordable prices, maturity, and limit options for developing the tourism sector and various businesses, including investment loans. Banks also create new loan support packages for the needs of the sector. The banking system continuously supports sectors with multiple credit products to maintain activities in the tourism sector, establish new tourism enterprises, renew the enterprises, and support renovation activities.

In this context, the study aims to determine the causality relationship among various psychological and economic sizes affecting the tourism sector in Turkey. Monthly data for the period 2011:01-2021:02 and the Toda Yamamoto Causality test were used in the study. Moreover, six different variables were preferred in the investigation of the total tourism loans financed by the banking system and the psychological and economic effects of the BIST tourism index. Among the variables, Industrial Production Index, BIST Tourism Index, Hotels and Restaurants (Tourism) Total Cash Loans, and consumer price index indicators (Restaurants and Hotels) represent economic reflections in the sector. The service sector confidence index and Turkey geopolitical risk index represent psychological effects. According to the causality test, a one-way causality relationship was obtained from the service sector confidence index to growth and consumer price index indicators and from the BIST Tourism Index to the service sector confidence index. Other findings include a one-way causality relationship from Hotels and Restaurants (Tourism) Total Cash Loans to CPI.
\end{abstract}

Keywords: Services confidence index, Turkey geopolitical risk index, Hotels and restaurants, Total cash loans, CPI, BIST tourism index

Jel Classification: A10, Z30, Z33

\title{
EXTENDED ABSTRACT
}

The tourism sector, which is described as a chimneyless industry, is an important area that affects the growth indicators of a country's economy. In terms of the sector, financial opportunities and service confidence perception are the subjects that should be examined. Financial support is provided to develop, support, and grow the tourism sector to contribute to economic growth. The banking system continuously supports sectors with various credit products to maintain activities in the tourism sector, establish new tourism enterprises, renew the enterprises, and support renovation activities. The tourism sector is an important sector for countries' economies with a foreign currency input. This sector provides employment opportunities, solving the unemployment problem by creating income. Among the subservice sectors in Turkey in general and the services sector in particular, tourism has an increasing share of gross domestic product (GDP).

In this context, the study aims to determine the causality relationship among various psychological and economic sizes affecting the tourism sector in Turkey. Monthly data for the period 2011:01-2021:02 and the Toda Yamamoto Causality test were used in the study. Moreover, six different variables were preferred in the investigation of the total tourism loans financed by the banking system and the psychological and economic effects of the BIST tourism index. As an indicator of economic growth, industrial production index, BIST tourism index, tourism total cash loans, and consumer price index (CPI) variables represent 
economic activities. The service sector confidence index and Turkey geopolitical risk index are important variables selected to represent psychological factors. According to the results of the analysis, a one-way causality relationship has been obtained from the service sector confidence index to growth and CPI indicators and from the BIST Tourism Index to the service sector confidence index. Other findings include a one-way causality relationship toward CPI from Hotels and Restaurants (Tourism) Total Cash Loans. The result of the analysis method used in the study shows that the effects on economic factors for the tourism sector are strengthened specifically by the service sector confidence index, which represents the psychological perception. Among the findings, the service sector confidence index is the cause of the hotel/restaurant price index. The result of the BIST Tourism Index's service sector confidence index supports this view. In other words, an increase in value in tourism companies traded on the stock exchange representing the financial sector can positively affect the services confidence index, whereas an increase in confidence can affect the price index by increasing sectoral activities. The share of the service sector in GDP in Turkey is undeniable. The importance of expectation and increased trust in the sectors increases and even provides a psychological perspective to the relationship between the two phenomena. In this context, confidence indices consisting of various criteria affect the value of companies in the stock exchange and the service sector. One of the more general findings is that the service sector confidence index is the cause of economic growth. This result emphasizes the increasing importance of perception and expectation, which is considered a psychological factor in economic growth in economic decision-makers. A causality relationship between tourism loans used by banks and economic growth has not been determined. In the study, tourism sector loans and company values are expected to have an indirect effect, although not directly, on economic growth. This notion will be explained by the change in price indices. Therefore, the loans used to increase the economic growth of tourism loans should be directed more to the areas that will encourage tourism investments. Moreover, banks should continue to finance investments in tourism enterprises renewed to provide employment growth with affordable price and maturity opportunities. Investment loans given to the tourism sector through banks will only reflect positively on economic growth when investments occur. Although Turkey is a country in demand with its geopolitical position and service potential, the sector still needs to be made more effective. In this context, in addition to various financial conveniences or incentives, policies that will increase the number of tourists visiting our country and the diversity of the visiting country should also be established. This research hopes to guide future studies by measuring and comparative analysis of the effects of tourism loans on economic activities using different countries or different analysis methods in new studies. 


\section{Giriş}

Küreselleşmeyle birlikte ekonomideki önemi ön plana çıkan turizm sektörü, 21. yüzyıl dünya ekonomisinde en hızlı gelişen sektörlerden biri olup gelişmiş ve gelişmekte olan ülkelerde ekonomik büyüme ile gelişmenin anahtarı olarak görülmektedir (Bahar, 2006, s.137-138). Turizm sektörüyle hizmet ihracatı yaparak daha fazla döviz girdisi ve dolayısıyla ulusal gelir sağlanması mümkündür (Fayed \& Fletcher, 2002, s.210). Yabancı turistlerin yapmış oldukları turizm amaçlı harcamalar ülkeye sağladığı döviz geliri açısından mal ihracatında olduğu gibi bir etki meydana getirmektedir. Bir başka deyişle, turizm görünmez bir ihracat kalemidir (Theobald, 2001). Ayrıca turizm sektörünün emek-yoğun özelliği, istihdamı artırıcı rolüyle işsizliği önlenmesi, ekonomide iş hacminin genişlemesi ve sektörlerin canlandırılması gibi pek çok ekonomik etkileri vardır (Ünlüönen \& Şahin, 2011, s.1; İçöz \& Kozak, 1998, s.219). Ekonomik büyümeye katkı sağlamak amacıyla turizm sektörünü geliştirmek, desteklemek ve sektörü büyütmek için finansal destekler sağlanmaktadır. Söz konusu finansal desteklerin başında banka kredileri ile turizm yatırım ve işletmelerinin teşvik edilmesi, düzenlenmesine yönelik turizm teşvikleri gelmektedir.

Türkiye ekonomisinde turizm sektörü, 1980 yılından sonra büyük bir gelişme göstermiş ve ekonomik sıkıntıların yaşandığı dönemlerde ülkeye büyük bir döviz girdisi sağlayarak dış ticaret açıklarının giderilmesi, işsizliğin azaltılması, ödemeler bilançosunun iyileştirilmesi yönünde olumlu katkılar sağlamıştır (Çımat \& Bahar, 2003, s.1). Bu bağlamda bankalar, turizm sektöründe yüksek maliyetli yenileme ve modernizasyon yatırımlarını finanse etme amaçlı uygun fiyat ve vadelerle vermiş oldukları turizm kredi ürünleri ile sektöre destek olmaktadirlar.

Türkiye'de toplam turizm gelirinin GSYİH (Gayri Safi Yurtiçi Hasıla) içindeki payı 2016 yılında \%2,6, 2017 yılında \%3,1, 2018 yılında \%3,8 iken 2019 yılında \%4,6 seviyesinde gerçekleşmiştir (TÜRSAB,2021). Bacasız sanayi olarak nitelendirilen turizm sektörü Türkiye' de 2018 yılında toparlanmaya başlamış, 2019 yılında 52 milyon turist ve 35 milyar dolarlık gelirle büyüme gerçekleştirmiştir. 2020 yılına gelindiğinde özellikle turist sayısında ve kişi başı harcamalarda pozitif beklenti mevcutken Çin'de ortaya çıkan ve hızla tüm dünyaya yayılan COVID-19 salgınında beklentiler revize edilmiştir (Deloitte, 2020). Diğer yandan bankacılık sektörü bu salgın döneminde de turizm sektörüne "Kredi Garanti Fonu" ile kredi desteği sağlamıştır.

Turizm sektörünün gelişmesi aynı zamanda diğer sektörlerinde gelişmesine olumlu katkılar sağlayacaktır. Turizm sektörünü hem doğrudan hem de dolaylı olarak ilgilendiren diğer işletmelerde turizmden elde ettikleri gelirler sayesinde ekonomik gelişmeyi desteklemektedir. (Arabacı, 2018). Bu nedenle çalışmamızda turizm sektörü seçilmiştir. 
Turizm sektörünün finansal ihtiyacını karşılamak için bankalar uygun krediler ve finansal hizmetler sunmaktadır.

$\mathrm{Bu}$ alanda literatürde yapılan çalışmalar incelendiğinde özellikle Türkiye'de turizm gelirleri ile ekonomik büyüme arasındaki ilişkinin araştırıldığı görülmektedir. Bu çalışmada Türkiye' de turizm sektörünü etkileyen psikolojik ve ekonomik çeşitli büyüklükler arasındaki nedensellik ilişkisinin araştırılmasının amaçlanmış olması nedeniyle diğer çalışmalardan farklı olarak literatüre katkı sağlayacağı düşünülmektedir. Genel itibariyle çalışmada, Türkiye'de Ocak 2011-Şubat 2021 dönemleri dikkate alınarak toplam turizm kredileri ile BIST turizm endeksinin psikolojik ve ekonomik büyümeye yansımaları araştırılmıştır. Bu amaçla çalışmada 6 farklı değişken seçilmiş ve çalışmada Todo-Yamamoto (1995) nedensellik testi yöntemi kullanılmıştır.

Çalışmada ekonomik büyüme göstergesi olarak sanayi üretim endeksi, otel ve restoranlara (turizm) verilen kısa, orta ve uzun vadeli nakdi kredileri ifade eden değişken olarak turizm toplam nakit kredileri, ekonomik faaliyetleri temsilen TÜFE, BIST turizm endeksi ile psikolojik faktörleri temsilen Hizmet sektörü güven endeksi ve Türkiye jeopolitik risk endeksi seçilmiş önemli değişkenlerdir. Çalışmada iki önemli kısıt söz konusudur. Bunlardan ilki çalışmanın Türkiye ile sınırlı olması bir diğeri ise incelenen dönem ile incelemeye konu olan değişkenlerdir. Turizm kredilerindeki gelişmelerin psikolojik ve ekonomik yansımalarının araştırıldığı çalışmadan elde edilen nedensellik ilişkisi sonucunda sunulan öneriler kapsamında çalışmanın literatüre katkı sağlayacağı öngörülmektedir. Çalışmanın giriş kısmında çalışmanın önemi ve amacı belirtilmiş, sonraki kısmı olan ikinci bölümde bankacılık sektörünün turizm sektörüne sağladığı krediler konusunda bilgilere yer verilmiştir. Üçüncü bölümde ilgili alandaki literatür çalışmaları incelenmiştir. Dördüncü bölümde çalışmada kullanılan yöntem ve veriler tanımlanmıştır. Beşinci bölümde analiz bulgularına yer verilmiştir. Sonuç kısmında ise çalışmadan elde edilen bilgiler kapsamında genel bir değerlendirme yapılmış, önerilere yer verilmiş, çalışmanın gelecek çalışmalar için önemi vurgulanmıştır.

\section{Banka Kredilerinin Turizm Sektöründeki Önemi ve Finansman Yapısı}

Bankacılık sektörü finansal sistemin en önemli aktörü konumundadır. Hızla gelişen dünya ekonomisinde bankacılık sektörünün önemi her geçen gün artmaktadır. Bankaların tasarruf sahiplerinden topladıkları fon fazlasını ekonomide fon ihtiyacı olan birimlere kullandırdıkları krediler ise bankaların en yaygın kullandığı temel ürünlerinden biridir (Uğurlu, 2020, s.120).

Genellikle banka kredilerinin ülkelerin ekonomik büyüme süreçlerinde önemli bir role sahip olduğu düşünülmekte olup literatürde bu görüş arz öncülü hipotez olarak bilinmektedir. 
Diğer yandan bankacılık sektörü aracılığıyla tasarrufların fon ihtiyacı olanlara yönlendirilmesi, yatırım stokunda dolayısıyla ekonomik büyümede artışa neden olacak ve banka kredi hacminde artış meydana gelecektir. Bu görüş ise literatürde talep takipli hipotez olarak bilinmektedir (Turgut, 2019). Keza Turizm sektöründeki konaklama ve yiyecek hizmetleri sektörüne yönelik bankaların tahsis ettiği yatırım kredilerinin ekonomik faaliyetlere olumlu yansımasının ekonomik büyümeye destek vereceği düşünülmektedir.

Turizm sektörünün önemli hizmet aktörlerinden biri olan konaklama işletmeleri ile yiyecek-içecek işletmeleri hem yatırım aşamasında hem de işletme aşamasında yenileme, genişleme ve modernizasyon yatırımlarının gerçekleştirilme zorunluluğunun bulunduğu işletmelerdir. Bundan dolayı ilgili yatırımların finansmanı devlet teşvikleri, işletmelerin öz kaynakları veya kredi kullanılarak sağlanmaktadır. Ayrıca konaklama ve yiyecek hizmetleri sektörü, talep yapısının sürekli değiştiği, belirsizlik ve riskin her zaman mevcut olduğu, maliyet ve giderlerin kontrolünün her geçen gün zorlaştığı ve kâr marjlarının ise gittikçe daraldığ 1 bir sektördür. Bütün bu bahsedilen unsurlar işletmelerin finansal kaynak ihtiyaçlarını arttırmaktadır. (Kandır, Karadeniz, Özmen, \& Önal, 2008; Karadeniz, 2012). Bankacılık sektörü turizm alanında faaliyet gösteren bu işletmelerin finansman ihtiyaçlarına yönelik çeşitli kredi ürünleri sunmaktadır. Turizm sektöründe yatırım maliyetlerinin yüksek olması nedeniyle bankalar bu sektörleri destekleyecek uygun vade ve faiz oranı ile kısa, orta ve uzun vadeli nakit kredi ve gayri nakdi limitleri tahsis etmektedir. Şekil 1'de Türkiye'deki turizm kredilerine yönelik bilgiler özetlenmiştir.

Şekil 1: 2005-2019 yılları arasındaki Türkiye’deki Turizm Sektörü Kredileri

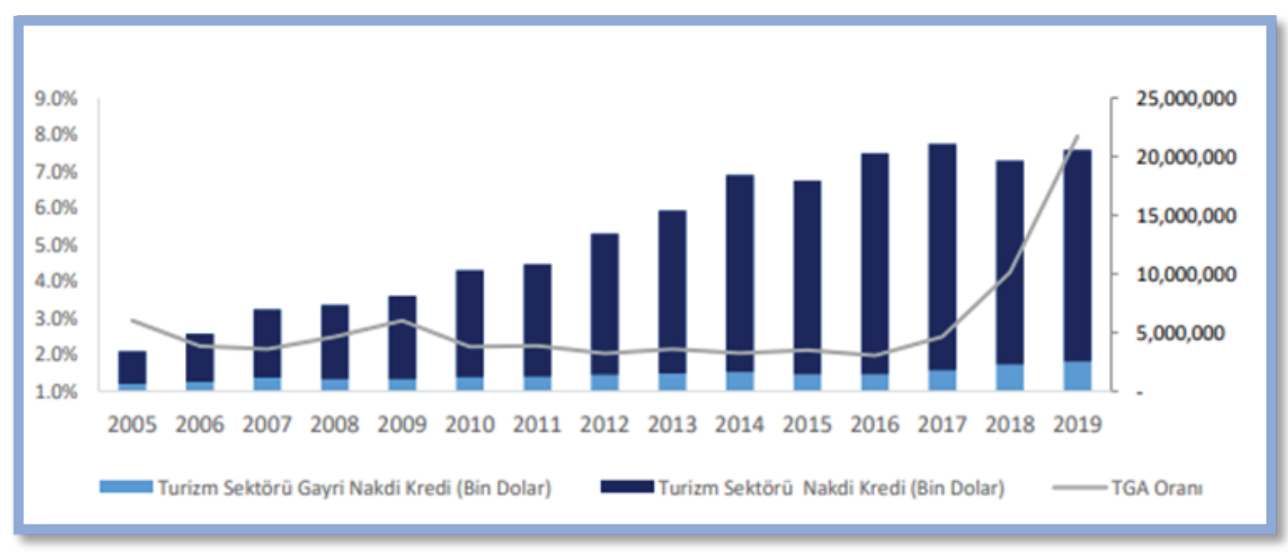

Kaynak: (BDDK; A\&T Bank,2020)

Şekil 1 incelendiğinde, turizm sektörü için kullandırılan nakit krediler 2019 yılında \%4.1 oranında artarak 18.1 milyar dolar seviyesine ulaşmıştır. Nakit krediler dolar bazında 2010 yılında \%28.5 ve 2012 yılında \%25.4 oranında artmış ve 2013 yılında ise $\% 15.4$ büyüme 
kaydetmiştir. Turizm sektörüne verilen gayri nakit krediler ise 2019 yılında 2.5 milyar dolara ulaşmıştır ve \%9.6 oranında büyüme sergilemiştir. Gayri nakit krediler yatırımlar için teminat olarak kullanıldığından oldukça önemlidir. Gayri nakit krediler son 3 yılda genellikle büyümüştür (A\&T Bank, 2020, s.15).

Tablo 1'de belirtildiği üzere özellikle de Covid-19 döneminde turizm sektöründe faaliyet gösteren işletmelere salgının olumsuz etkisini azaltmak amaçlı kredi paketleri hazırlanmıştır.

Tablo 1: Turizm Destek Paketi Kredi Limiti ve Kefalet Oranı

\begin{tabular}{|c|c|c|c|c|}
\hline Yararlanıcı & Ciro & $\begin{array}{l}\text { Kefalet Üst Limit } \\
\text { (TL) }\end{array}$ & $\begin{array}{l}\text { Kredi Üst Limit } \\
\text { (TL) }\end{array}$ & Kefalet Oranı \\
\hline \multirow{7}{*}{ KOBİ/KOBİ DIŞI } & $0-3$ milyon TL & 200.000 & 250.000 & \multirow{7}{*}{$80 \%$} \\
\hline & 3 - 10 milyon TL & 800.000 & 1.000 .000 & \\
\hline & 10 - 25 milyon TL & 2.400 .000 & 3.000 .000 & \\
\hline & 25 - 50 milyon TL & 4.000 .000 & 5.000 .000 & \\
\hline & 50 - 125 milyon TL & 8.000 .000 & 10.000 .000 & \\
\hline & 125 milyon TL ve üzeri & 16.000 .000 & 20.000 .000 & \\
\hline & Konaklama & 32.000 .000 & 40.000 .000 & \\
\hline
\end{tabular}

Kaynak: (KGF, Turizm Destek Paketi)

Covid-19 döneminde Türkiye'deki bankalar (Ziraat Bankası, Halkbank, Vakıfbank, Akbank, Yapı Kredi Bankası, Denizbank, QNB Finansbank, TEB, Garanti BBVA, İş Bankası, Albaraka Türk Katılım Bankası, Kuveyt Türk Katılım Bankası, Türkiye Finans Katılım Bankası, Vakıf Katılım Bankası, Ziraat Katılım Bankası) turizm sektörüne Kredi Garanti Fonu ile kredi sağlamış ve finansal anlamdaki desteklerini çeşitlendirerek turizm destek paketi uygulamalarını başlatmıştır. Krediler azami 12 ay ödemesiz dönem olmak üzere toplam 36 ay vadeli olarak kullandırılmaktadır (KGF, 2021).

\section{Literatür Taraması}

Turizm sektörüne yönelik literatürde yapılan çalışmalar incelendiğinde özellikle turizm gelirleri odaklı ekonomik çalışmalar dikkat çekmekte olup yine sektörde finansman sorununa vurgu yapılmaktadır. Yılmaz (2007), Türkiye'de turizm sektöründe yer alan 47 işletmeyi kapsayan anket yöntemini kullandığı ve söz konusu işletmelerin finansman sorunları ile kredi olanaklarından yararlanma düzeyini incelediği çalışmasında; bankalar yoluyla finansmanda özellikle kredi temini ve yüksek maliyetlerin sektörü olumsuz etkilediği sonucuna ulaşmıştır. Turizm sektör değişkenleri ve ekonomik büyüme arasındaki ilişkinin incelendiği çalışmalardan Gündüz ve Hatemi (2005), Türkiye için 1963- 2002 dönemini kapsayan çalışmalarında, turizmden ekonomik büyümeye doğru tek yönlü nedensellik ilişkisi tespit etmişlerdir. Brida ve ark. (2008), yaptıkları çalışmalarında VAR analizi ve Granger (1969) nedensellik testi yöntemini tercih etmişlerdir. Yöntem sonucunda 
Meksika'daki turizm harcamaları ve reel döviz kuru ile reel GSYİH arasında ilişki olduğunu tespit etmişlerdir. Chen ve Chiou- Wei’nin (2009), yaptıkları çalışmalarında Granger (1969) nedensellik ile Var analizini kullanmışlardır. Çalışma sonucunda hem Tayvan'da hem de Güney Kore'de turizmin ekonomik büyümeyi beraberinde getirdiği sonucuna ulaşılmıştır.

Bahar ve Bozkurt (2010) Türkiye'nin de içine olduğu 21 ülke için 1998-2005 dönemi için yaptıkları çalışma sonucunda GOÜ’ler açısından turizm gelirleri ve ekonomik büyüme arasında pozitif ve anlamlı bir ilişki tespit etmişlerdir. Samimi, Sadeghi ve Sadeghi, (2011), 1995-2009 dönemleri için yaptıkları çalışmalarında gelişmekte olan ülkelerdeki ekonomik büyüme ve turizm arasındaki ilişkiyi analiz etmek için P-VAR yöntemini kullanmışlardır. Çalışma sonucunda, turizm ve ekonomik büyüme arasında çift yönlü nedensellik ilişkisi tespit edilmiştir. Arslantürk ve Atan (2012)'ın yapmış oldukları çalışmalarında, turizm gelirleri ile ekonomik büyüme arasında nedensellik ilişkisinin olduğu sonucuna ulaşılmıştır. Çoban ve Özcan (2013) çalışmalarında Türkiye'de 1963-2010 dönemleri arasındaki turizm ve ekonomik büyüme arasındaki ilişkiyi eş bütünleşme ve nedensellik analizi yöntemiyle analiz etmişlerdir. Uzun dönemde turizm sektörünün ekonomik büyümenin önemli bir nedeni olduğu ancak kısa dönemde iki değişken arasında bir ilişki olmadığı sonucuna ulaşmışlardır.

Bozgeyik ve Yoloğlu (2015), Ayaydın, Baltacı, Pala ve Barut (2019), çalışmalarında turizm gelirlerinden ekonomik büyümeye doğru tek yönlü nedensellik ilişkisi bulurken Balıkçığlu ve Oktay (2015) çalışmalarında tersi yönde yani ekonomik büyümeden turizm gelirlerine doğru tek yönlü nedensellik ilişkisi olduğu sonucuna ulaşmışlardır. Turizm sektörüne yönelik yapılan çalışmaların ekonomik büyümeye etkisi söz konusu olduğunda turizm gelirleri üzerinde yoğunlaşıldığı görülmekle beraber söz konusu gelirleri elde etmede kullanılan finansman yöntemlerinden biri olan banka kredileri, çalışılan nadir konulardan biridir. Bu bağlamda Kandemir, Arifoğlu ve Cambaz (2018) Türkiye' de mevcut katılım bankaları tarafından, içinde turizm sektörünün de olduğu 10 farklı sektöre kullandırılan krediler ve ekonomik büyüme arasındaki nedenselliği inceledikleri çalışmalarında turizm sektörüne verilen krediler ile büyüme arasında nedensellik ilişkisinin olmadığını tespit etmişlerdir. Pata (2020) çalışmasında turizme dayalı büyüme hipotezinin Türkiye için geçerliliğini ARDL Sınır testi yaklaşımı ile tespit etmiş olup ekonomik büyümede turizmin itici gücüne vurgu yapmaktadır.

Farklı ülkeler kapsamında turizm sektörü ve ekonomik büyümenin araştırıldığ 1 çalışmalardan De Vita ve Kyaw (2016) 1995-2011 yılları arasında 129 ülkeyi kapayan analizlerinde turizmin olumlu etkisinin sadece orta ve yüksek gelirli ülkeler için önemli iken düşük ekonomik kalkınma seviyelerinde turizmin GSYİH büyümesine katkıda bulunmadığ sonucuna ulaşmıştır. Ohlan (2017) 1960-2014 döneminde finansal kalkınmanın göreceli 
önemini göz önünde bulundurarak Hindistan'da turizm ve ekonomik büyüme arasındaki ilişkiyi araştırdığı çalışmasında turizmin hem uzun hem de kısa vadede Hindistan'da ekonomik büyümeyi teşvik ettiğini tespit etmiştir. Fareed, Meo, Zulfiqar, Shahzad ve Wang (2018) Turizm, terörizm ve Tayland'ın ekonomik büyümesi arasındaki asimetrik ilişkiyi araştırdıkları çalışmalarında ARDL eşbütünleşme tekniği kullanılarak 1990 ile 2017 arasında değişen yıllık bir veri seti kullanmışlardır. Çalışmanın sonucu, turizm ve terörizmdeki olumsuz ve olumlu değişiklikler nedeniyle ekonomik büyümenin değiştiğine vurgu yapmaktadir.

Hizmetler sektörünün etkileyenleri üzerine yapılan çalışmalar son yıllarda ekonomik değişkenler dışında güven ve beklenti gibi psikolojik faktörlerle de ilişkilendirilmektedir. Söz konusu değişkenlerden biri Hizmet Sektörü Güven Endeksi olup üzerine yapılan çalışmaların sayıca azlığı dikkat çekmektedir. Bu çalışmalardan İskenderoğlu ve Akdağ (2017) 2015:05-2017:08 zaman aralığında finansal hizmetler güven endeksi ile BIST-100 endeksi arasındaki nedensellik ilişkinin varlığını test ettikleri çalışmalarında finansal hizmetler güven endeksi ile BIST-100 arasında uzun dönem karşılıklı nedensellik ilişkisinin varlığ1 sonucuna ulaşmışlardır. Eyüboğlu ve Eyüboğlu (2018) 2011:01- 2017:12 dönemi için hizmet sektörü güven endeksi (HGE) ile BIST Hizmetler sektörü alt endeksleri arasındaki eşbütünleşme ilişkisini inceledikleri çalışmalarında HGE ile BIST Turizm endeksi arasında eşbütünleşme ilişkisinin varlığını tespit etmişlerdir. Kısa dönemde güvendeki artışın turizm endeksini pozitif yönde etkilemesi ve Toda-Yamamoto (1995) testi ile analiz edilen HGE ile BIST Turizm endeksi arasında çift yönlü nedensellik ilişkisinin varlığ 1 diğer bulguları arasindadir.

Türkiye dışında diğer ülkelerin turizm sektörüne ilişkin güven ve ekonomik değişkenlerinin ilişkilendirildiği çalışmalardan Croce (2016) turizm talep tahminlerinde turizm güven endeksinin etkisini ölçmeye çalışmış ve artan güven unsurunun özellikle turist gelişlerinde pozitif etki sağladığını tespit etmiştir. Aharon (2020) Tüketici güven endeksi, korku endeksi ve küresel belirsizlik endeksi gibi seçilmiş güven ve belirsizlik göstergelerinin turizm ve eğlence sektörüne olan duyarlılığını ölçtüğü çalışmasında ABD halka açık firmalarından oluşan bir portföy oluşturmuş ve duyarlılık ve belirsizlik önlemlerindeki değişikliklerin sektör şirket performansları arasında eş zamanlı ve öngörücü ilişkilerin bulunduğunu tespit etmiştir. Gholipour, Nunkoo, Foroughi ve Daronkola (2021), seçilmiş ülkelerin ekonomik politika belirsizliği ve tüketici güvenindeki değişikliklerin Afrika ülkelerine turizm akışları üzerindeki etkisini araştırdıkları çalışmalarında 2005-2019 dönemindeki verileri kullanarak ve panel farkı genelleştirilmiş momentler yöntemi yöntemini uygulamışlardır. Analiz sonuçları Kanada, Çin, Fransa, Japonya, Rusya ve Birleşik Krallık’taki (İngiltere) tüketici güvenindeki olumlu bir değişimin bu ülkelerden 25 Afrika ülkelerine turizm kalkışları üzerinde olumlu bir etki meydana getirirken, Kanada, 
Rusya, İspanya ve İngiltere'deki artan belirsizliğin, bu ülkelerden Afrika ülkelerine turist kalkışları üzerinde olumsuz bir etkisi olduğunu göstermektedir.

\section{Veriler ve Yöntem}

Çalışmada Ocak 2011 - Şubat 2021 dönemi aylık verileri kullanılarak Eviews 9 paket programı aracı̆̆ıyla ilk olarak değişkenlerin durağan oldukları mertebeyi belirlemek amacıyla Dickey ve Fuller (1979, 1981) tarafından geliştirilen Augmented Dickey-Fuller (ADF) birim kök testi uygulanmıştır. Durağanlık sınaması sonrasında değişkenler arasındaki nedensellik ilişkisini tespit etmek için Toda-Yamamoto (1995) tarafından geliştirilen nedensellik testi uygulanmıştır.

\subsection{Veriler}

Çalışma Ocak 2011 - Şubat 2021 dönemi aylık verilerini kapsamaktadır. Çalışmada kullanılan değişkenlerin logaritması alınmış ve analize hazır hale getirilmiştir. Çalışmada kullanılan değişkenler ve elde edildikleri yerler Tablo 2'de özetlenmiştir.

Tablo 2: Değişkenler ve Kısaltmaları

\begin{tabular}{lcc}
\hline Değişkenler & Kısaltma & Alındığı Yer \\
\hline Sanayi Üretim Endeksi & SÜE & TÜIK \\
BIST Turizm Endeksi & XTRZM & INVESTING \\
Otel ve Restoranlar (Turizm) Toplam Nakdi Kredileri & KREDİ & BDDK \\
Harcama Grubuna Göre TÜFE (Lokanta ve Oteller) & TÜFE_LO & TÜİK \\
Hizmet Sektörü Güven Endeksi & HGE & TÜİK \\
Türkiye Jeopolitik Risk Endeksi & T_GPR & MATTEO IACOVIELLO \\
\hline
\end{tabular}

Sanayi Üretim Endeksi (SÜE): Tüm Türkiye'yi kapsayan SÜE ile ekonomide meydana gelen gelişmelerin ve uygulanan ekonomik politikaların etkilerinin ölçülmesi amaçlanmaktadır. Madencilik ve taşocakçılığı, imalat, elektrik, gaz, buhar ve iklimlendirme üretimi ve dağıtımı sektörlerini kapsamakta ve büyümeyi temsil etmektedir.

BIST Turizm Endeksi (XTRZM): BIST hizmetler endeksi 7 alt endeksten oluşmaktadır. $\mathrm{Bu}$ endekslerden biri olan XTRZM'de turizm sektöründe faaliyet gösteren halka açık 7 şirket işlem görmektedir.

Otel ve Restoranlar (Turizm) Toplam Nakdi Kredileri (KREDI): BDDK'nın sektörel kredi dağılımında otel ve restoranlar (turizm) sektörüne verilen kısa, orta ve uzun vadeli nakdi kredileri ifade etmektedir.

Harcama Gruplarına Göre TÜFE (Lokanta ve Oteller)(TÜFE_LO): TÜİK tarafindan 2003 yılından itibaren piyasada tüketime konu olan mal ve hizmetlerin fiyat değişimleri ölçülerek enflasyon oranının hesaplanması amacıyla harcama gruplarına göre TÜFE endeks 
sonuçları yayınlanmaktadır. Çalışmada lokanta ve oteller harcama grubu endeks verileri kullanılmıştır.

Hizmet Sektörü Güven Endeksi (HGE): Sektörel güven endekslerinden biri olan HGE, hizmet sektörü eğilim anketi ile yöneticilerin mevcut durum ve geçmiş değerlendirmeleri ile gelecek beklentilerini yansitmaktadır.

Türkiye Jeopolitik Risk Endeksi (T_GPR): 2016 yılında Caldara ve Iacoviello (2018) tarafından geliştirilen Jeopolitik Risk Endeksi, uluslararası ilişkilerin seyrini etkileyen savaş, terörizm ve gerilimlerle ilişkili riski yansıtmaktadır. Gazetelerde yer alan jeopolitik olay ve bunlardan kaynaklı riskleri ele alan olay sayıları ile oluşturulan endeks, 1985 yılından başlayarak 11 gazetenin elektronik arşivlerinin taranması ile aylık olarak hesaplanmaktadır. Jeopolitik risk endeksinin yanı sıra 19 ekonomi için ülkelere özgü jeopolitik risk endeksleri de yayınlanmaktadır.

\subsection{Yöntem}

Değişkenlerin bir kısmının durağan bir kısmının durağan dış1 olması değişkenler arasındaki nedensellik sınamasında dinamik bir yaklaşımın kullanılmasını gerekli kılmaktadır. Granger (1969) nedensellik testi gibi standart nedensellik testlerinin uygulanabilmesi ancak değişkenlerin durağan olması ile mümkün olmaktadır. Durağan olmayan değişkenlerde ise serilerin farkları alınarak durağanlaştırılmakta ve bu durum da serilerin dinamik yapısının bozulmasına neden olmaktadır (Çınar, Yetkin \& Bektaş, 2019, s.360). Toda Yamamoto (1995) nedensellik testi bu sorunu ortadan kaldırarak değişkenlerin durağanlık derecesine bağlı olunmadan nedensellik sınamasının yapılmasına olanak sağlamaktadır.

Toda-Yamamoto (1995) nedensellik testinde iki temel aşama bulunmaktadır. İlk olarak VAR modeli kurularak uygun gecikme uzunluğunun belirlenmesi daha sonra serilerin en yüksek tümleşme derecesinin $\left(\mathrm{d}_{\max }\right)$ modele dahil edilmesidir. Toda-Yamamoto (1995) modeli aşağıdaki gibi tanımlanmaktadır: (Çınar ve ark., 2019, s.360)

$$
\begin{aligned}
& Y_{t}=\alpha_{0}+\sum_{t=1}^{p+d_{\text {max }}} \alpha_{1(t+d)} Y_{t-(t+d)}+\sum_{t=1}^{p+d_{\max }} \alpha_{2(t+d)} X_{t-(t+d)}+\varepsilon_{1 t} \\
& X_{t}=\beta_{0}+\sum_{t=1}^{p+d_{\max }} \beta_{1(t+d)} Y_{t-(t+d)}+\sum_{t=1}^{p+d_{\max }} \beta_{2(t+d)} X_{t-(t+d)}+\varepsilon_{2 t}
\end{aligned}
$$

Denklemde $\mathrm{p}$, VAR modelin derecesini, $\mathrm{d}_{\max }$ ise değişkenlerin en yüksek tümleşme mertebesini göstermektedir. VAR $\left(\mathrm{p}+\mathrm{d}_{\max }\right)$ olarak tanımlanan modelde (1) nolu denklemle $\mathrm{X}$ değişkeninden $\mathrm{Y}$ değişkenine nedensellik (2) nolu denklemle $\mathrm{Y}$ değişkeninden $\mathrm{X}$ değişkenine olan nedensellik test edilmektedir. 


\section{Bulgular}

Tablo 3: ADF ve KPSS Birim Kök Testi Sonuçları

\begin{tabular}{|c|c|c|c|c|c|c|c|}
\hline \multirow{5}{*}{$\mathrm{ADF}$} & DEĞIŞSENLER & SÜE & XTRZM & KREDİ & TÜFE_LO & HGE & T_GPR \\
\hline & \multirow{2}{*}{ DÜZEY } & $(-8.331964)$ & $(-0.180952)$ & $(-2.669989)$ & $(6.555550)$ & $(-4.830577)$ & $(-7.280980)$ \\
\hline & & {$[0.0000]^{*}$} & {$[0.9928]$} & {$[0.2510]$} & {$[1.0000]$} & {$[0.0007]^{*}$} & {$[0.0000]^{*}$} \\
\hline & \multirow{2}{*}{ BİRİNCİ FARK } & & $(-10.57140)$ & $(-10.58475)$ & $(-2.332496)$ & & \\
\hline & & & {$[0.0000]^{*}$} & {$[0.0000]^{*}$} & {$[0.0196]^{* *}$} & - & \\
\hline & DÜZEY & $(0.211171)$ & $(0.227582)$ & $(0.190003)$ & $(0.238714)$. & $(0.133824)$ & $(0.193043)$ \\
\hline & BİRINCII FARK & & $(0.097421)$ & & $(0.056964)$ & & \\
\hline
\end{tabular}

*, ** ve *** değerleri sırasıyla $\% 1, \% 5$ ve $\% 10$ hata paylarında serilerin durağanlıklarını göstermektedir. Parantez içindeki değerler, ADF ve KPSS birim kök testleri için test istatistiklerini, köşeli parantez içindeki değerler ise olasıllk değerlerini göstermektedir. ADF için optimum gecikme uzunluğu Schwarz Bilgi Kriterine (SIC) göre belirlenmiştir. KPSS için Bartlett Kernel yöntemi ve band genişliğinin belirlenmesinde Newey-West Bandwidth kriteri kullanılmıştır. KPSS için kritik değerler $\% 1$ hata payında; $0.2160, \% 5$ hata payında $0.1460, \% 10$ hata payında ise 0.1190 'dir. KPSS testinde sabit ve trendli model kullanılmıştır.

Çalışmada değişkenlere Dickey ve Fuller (1979, 1981) tarafından geliştirilen Genişletilmiş Dickey-Fuller (ADF) birim kök testi ve Kwiatkowski, Phillips, Schmidt ve Shin (1992) tarafından geliştirilen KPSS birim kök testleri uygulanmıştır. ADF birim kök testi uygulanırken ilk olarak değişkenlerin deterministik bileşenleri ile kritik değerleri karşılaştırılmıştır. ADF birim kök testi için deterministik bileşenlerde kritik değerler sabit ve trendli modelde 2,38, sabitli modelde 2,16'dır. Uygulanan hiyerarşiye göre SÜE, HGE ve T_GPR değişkenleri sabit ve trendli modelde $\% 1$ düzeyinde sıfır hipotezinin reddedildiği yani serilerin düzeyde durağan olduğu görülmüştür. XTRZM ve KREDİ değişkenleri, sabit ve trendli modelde sıfır hipotezi reddedilemeyerek durağan dişı oldukları, serilerin birinci farklarının alınarak durağanlaştıkları tespit edilmiştir. TÜFE_LO değişkeni ise deterministik bileşen içermemekte ve birinci farkında durağanlaşmaktadır. KPSS birim kök testi sonuçlarına göre de XTRZM ve TÜFE_LO değişkenleri birinci farklarında durağanlaşırken diğer değişkenler düzey değerlerinde durağandır. Birim kök testi sonuçlarına göre değişkenler farklı düzeylerde durağan hale gelmektedir. Bu nedenle nedensellik sınaması için Toda-Yamamoto (1995) nedensellik sınaması kullanılarak değişkenlerin fark alınması nedeniyle ortaya çıkabilecek bilgi kaybının önüne geçilmiştir.

Tablo 4: Gecikme Uzunluğunun Tespiti

\begin{tabular}{lcccccc}
\hline $\begin{array}{c}\text { Gecikme } \\
\text { Uzunluğu }\end{array}$ & LogL & LR & FPE & AIC & SC & HQ \\
\hline 0 & 293.6011 & NA & $2.59 \mathrm{e}-10$ & -5.045634 & -4.901623 & -4.987188 \\
1 & 1086.079 & 1487.634 & $4.47 \mathrm{e}-16$ & -18.31718 & $-17.30910^{*}$ & $-17.90806^{*}$ \\
2 & 1137.842 & 91.71942 & $3.41 \mathrm{e}-16^{*}$ & $-18.59371^{*}$ & -16.72158 & -17.83392 \\
3 & 1168.557 & 51.19198 & $3.79 \mathrm{e}-16$ & -18.50100 & -15.76480 & -17.39053 \\
4 & 1203.757 & $54.96249^{*}$ & $3.94 \mathrm{e}-16$ & -18.48697 & -14.88671 & -17.02583 \\
5 & 1234.158 & 44.26688 & $4.52 \mathrm{e}-16$ & -18.38873 & -13.92441 & -16.57691 \\
6 & 1263.510 & 39.65150 & $5.41 \mathrm{e}-16$ & -18.27211 & -12.94372 & -16.10961 \\
7 & 1297.041 & 41.76693 & $6.17 \mathrm{e}-16$ & -18.22879 & -12.03634 & -15.71563 \\
8 & 1329.565 & 37.08848 & $7.42 \mathrm{e}-16$ & -18.16781 & -11.11129 & -15.30396
\end{tabular}


Tablo 4 verilerine göre optimal gecikme uzunluğu iki olarak belirlenmiştir. Gecikme uzunluğunun belirlenerek yapılan VAR analizinde otokorelasyon sorununun olup olmadığının tespiti için LM testi uygulanmıştır.

Tablo 5: Otokorelasyon LM testi

$\begin{array}{lcc}\text { Gecikme Uzunluğu } & \text { LM Test İstatistiği } & \text { Olasılık Değeri } \\ 1 & 42.51107 & 0.2110 \\ 2 & 43.50238 & 0.1823 \\ 3 & 40.11823 & 0.2926 \\ 4 & 42.93542 & 0.1983\end{array}$

Optimal gecikme uzunluğunda otokorelasyon sorunu bulunmamaktadır. Ayrıca optimal gecikme uzunluğunda VAR modelinde AR polinomunun ters kökleri çember içerisinde yer almaktadır.

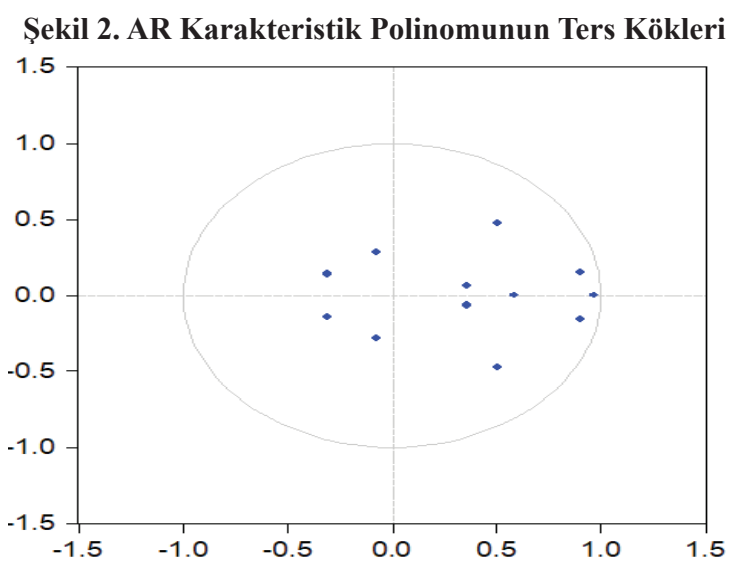

Optimal gecikme uzunluğuna değişkenlerin maksimum bütünleşme derecelerinin eklenmesi ile Toda-Yamamoto (1995) nedensellik testi uygulanmış ve sonuçları Tablo 6' da özetlenmiştir.

Tablo 6: Toda-Yamamoto Nedensellik Sonuçları

\begin{tabular}{|c|c|c|c|c|c|}
\hline Bağımlı Değişken & $\begin{array}{l}\text { Bağımsız } \\
\text { Değişken }\end{array}$ & p+dmax & $\begin{array}{l}\text { Ki-kare Test } \\
\text { İstatistiği }\end{array}$ & $\begin{array}{l}\text { Olasılık } \\
\text { Değeri }\end{array}$ & Nedensellik Yönü \\
\hline HGE & XTRZM & \multirow{2}{*}{$2+1$} & ‘'19.00670 & $0.0001^{*}$ & \\
\hline XTRZM & HGE & & ‘ 1.845212 & 0.3975 & XTRZM \\
\hline SÜE & HGE & \multirow{2}{*}{$2+1$} & 10.42677 & $0.0054 *$ & \\
\hline HGE & SÜE & & 1.805585 & 0.4054 & HGE \\
\hline TÜFE_LO & HGE & \multirow{2}{*}{$2+1$} & 15.01673 & $0.0005^{*}$ & \multirow{2}{*}{ HGE } \\
\hline HGE & TÜFE_LO & & 0.113635 & 0.9448 & \\
\hline TÜFE_LO & KREDİ & \multirow{2}{*}{$2+1$} & 31.21846 & $0.0000^{*}$ & \multirow{2}{*}{ KREDİ } \\
\hline KREDİ & TÜFE_LO & & 2.044759 & 0.3597 & \\
\hline
\end{tabular}


Toda-Yamamoto (1995) nedensellik sonuçlarına göre XTRZM'den HGE'ne doğru nedensellik ilişkisi tespit edilmiştir. Bu sonucu Eyüboğlu ve Eyüboğlu (2018) çalışması ile desteklemektedir. Ayrıca HGE'den SÜE ve TÜFE_LO'ya doğru; KREDİ değişkeninden ise TÜFE_LO'ya doğru tek yönlü nedensellik ilişkisi bulunmaktadır. Çalışmada T_GPR ile diğer değişkenler arasında nedensellik ilişkisi tespit edilememiştir.

\section{SONUÇ}

Turizm sektörü ülke ekonomilerinin büyüme göstergelerini etkileyen önemli bir alan olup gerek finansal firsatlar gerekse hizmet güven algısı, sektör açısından incelenmesi gereken konu niteliği taşımaktadır. Çalışmada Türkiye'de turizm sektöründe yer alan işletmelerin finansman alternatifleri arasında bulunan turizm kredileri, BIST Turizm Endeksi ve otel/lokanta hizmetlerine yönelik fiyat endeksi ekonomik faaliyetleri temsil ederken hizmet güven endeksi psikolojik faktörleri göstermektedir. Bu bağlamda kullanılan analiz yöntemi sonucunda turizm sektörüne yönelik ekonomik faktörler üzerine etkilerin özellikle psikolojik algıyı temsil eden hizmet sektörü güven endeksi ile güçlendiği tespit edilmiştir. Bulgular arasında yer alan hizmet sektörü güven endeksinin otel-lokantacılık fiyat endeksinin nedeni olması ve BIST Turizm Endeksinin Hizmet Sektörü Güven Endeksinin nedeni sonucu bu görüşü destekler niteliktedir. Daha açık bir ifade ile finansal sektörü temsilen borsada işlem gören turizm firmalarındaki değer artışı hizmetler güven endeksini pozitif yönde etkileyebilmekte artan güven ise sektörel faaliyetleri artırarak fiyat endeksini etkileyebilmektedir.

Litaratürde turizm ile büyüme arasındaki ilişkiyi araştıran çalışmalarda genellikle VAR analizi yöntemi, Granger (1969) nedensellik yöntemi ve ARDL yöntemi kullanılmıştır. Son zamanlarda bu yöntemlerle birlikte farklı yöntemlerde kullanılmaktadır. Çalışmada diğer yöntemlerden farklı olarak Toda-Yamamoto (1995) nedensellik testi yöntemi kullanılmıştır. Söz konusu yöntem değişkenlerin durağanlık derecesine bağlı olunmadan nedensellik sınamasının yapılmasına olanak sağlaması açısından önem arz etmektedir. Analiz sonucunda yer alan bulgular doğrultusunda hizmet sektörü güven endeksi büyümenin nedeni olup söz konusu sonuç teorik anlamda beklenen bir durumdur. Turizm firmalarının değerindeki değişmenin hizmet sektöründeki güveni etkilemesi ve güvenin de büyümeye olan etkisi dolaylı yoldan turizm firmalarının büyüme üzerindeki etkisini göstermektedir. Bu sonuç turizm ile büyüme arasında doğrudan veya dolaylı ilişki bulan Gündüz ve Hatemi (2005), Bozkurt (2011), Samimi ve ark. (2011), Bozgeyik ve ark. (2015), Ohlan (2017), Fareed ve ark. (2018) ve Ayaydın ve ark. (2019) çalışmalarını desteklemektedir.

Bankalarca kullanılan turizm kredileri ve ekonomik büyüme arasında bir nedensellik ilişkisi tespit edilememiş olup Kandemir ve ark. (2018) Türkiye için yaptıkları çalışmalarında 
benzer sonuca ulaşmışlardır. Söz konusu sonuç iki farklı açıdan değerlendirilmekte olup görüşlerden biri turizme dayalı hipotez olurken bir diğeri ekonomik büyümeye dayalı turizm hipotezidir. Turizm kredilerinin ekonomik büyümenin nedeni olmaması turizmin bir anlamda kalkınmada her ne kadar önemli bir sektör olsa da ancak kamu politikaları ile desteklenmesi ya da bankalarca verilen düşük faizli krediler sayesinde azalan maliyetlerle desteklenmesi sonucunda oluşan ekonomik büyümenin, turizm sektörüne katkı yapacağı düşünülmektedir.

Türkiye’ de hizmet sektörünün GSMH içindeki payı yadsınamayacak kadar yüksek olup sektörlere yönelik beklenti ve artan güven olgusunun önemi artmakta hatta bir anlamda iki olgu arasındaki ilişkiye psikolojik bir bakış açısı kazandırmaktadır. Bu bağlamda çeşitli kriterlerden oluşan güven endeksleri gerek borsa gerekse hizmet sektöründe firmaların değerini etkilemektedir. Keza çalışmada elde edilen bulgulardan biri de borsa da işlem gören turizm firma menkul kıymetlerindeki değişimin hizmet sektörü güven endeksinin nedeni olduğudur. Daha açık ifadeyle turizm sektöründe meydana gelen canlılık firma değerlerini artırırken sektöre olan beklentinin de pozitif yönde olacağı düşünülmektedir. Diğger yandan sektöre olan güven duygusundaki azalma ya da negatif beklentilerin talep yolu ile fiyatlara yansıyacağı da bulgular arasında olup hizmet sektörü güven endeksi otel/lokanta fiyat endeksinin nedeni olarak tespit edilmiştir.

Daha genel bulgulardan biri ise hizmet sektörü güven endeksinin ekonomik büyümenin nedeni olduğudur ki bu bulgu ekonomik büyüme noktasında psikolojik faktör olarak değerlendirilen alg1 ve beklentinin ekonomik karar alıcılarda artan önemine vurgu yapmaktadır. Her ne kadar çalışmada turizm sektör kredileri ve firma değerlerinin ekonomik büyüme noktasında doğrudan etkisi olmasa da dolaylı etki sağlayacağı düşünülmekte olup bunun fiyat endekslerindeki değişimle açıklanacağı düşünülmektedir. Bu nedenle turizm kredilerinin ekonomik büyümeyi artırması için kullandırılan kredilerin turizm yatırımlarını teşvik edecek alanlara daha çok yönlendirilmesi, istihdam artışı sağlayacak şekilde yenilenen turizm işletmelerine yönelik yatırımların uygun fiyat ve vade olanakları ile bankalarca finanse edilmeye devam edilmesi önem arz etmektedir. Ayrıca turizm sektörüne yönelik yeni turizm destek paketlerini oluşturacak uygulamalara ve bu alanda banka içi ve banka dişı kaynaklardan yararlanılmaya da devam edilmelidir. Bankalar aracılığıyla turizm sektörüne verilen yatırım kredileri ancak yatırımlar gerçekleştiğinde ekonomik büyümeye olumlu olarak yansıyacaktır. Literatürde yapılan pek çok çalışmada görüleceği üzere kredilerin verimli alanlara kanalize edilmesi ve kredilerin ekonomik büyümeyi hızlandıracak yatırımlara aktarılması yoluyla ekonomik büyüme gerçekleşebilecektir.

Ülke ekonomik büyümesinde beklenen artışın sağlanmasında katkısı olan en belirgin sektör hizmet sektörü olmakla beraber turizm bunun en önemli alt kalemlerinden biridir. 
Türkiye gerek jeopolitik konumu gerekse hizmet potansiyeli ile talep gören bir ülke olmasına karşın yine de sektörün daha etkin hale getirilmesi gerekmektedir. Bu bağlamda çeşitli finansal kolaylıklar ya da verilen teşvikler yanında güveni artıracak olan siyasal ve sosyal konular kapsamındaki belirsizliğin azaltılması önem arz etmektedir. Çalışmanın bundan sonraki gelecekteki çalışmalar için yol gösterici olduğu düşünülmektedir. Yeni çalışmalarda farklı ülkeler veya farklı analiz yöntemleri kullanılarak turizm kredilerinin ekonomik büyüme üzerine yansımalarının ölçülmesi ve karşılaştırmalı analizi gerçekleştirilebilir. Turizm sektörünün ekonomiye olumlu katkısını sağlayabilmek için turizm yatırımlarının finansmanına yönelik bankaların farklı finansal ürün ve hizmetleri geliştirilmesi yönündeki çalışmaları önemlidir. Ayrıca uzun vadeli yatırımların finansmanına yönelik yurtdışı finansman olanaklarına da ağırlık verilmesi yönündeki uygulamalara da devam edilmelidir. Bununla birlikte turizmin gelişimini hızlandırmak için vergi indirimi, faiz desteği konularında devlet politikaları uygulamalarının ekonomiye olumlu yansımaları olacaktır. Buna ek olarak iç ve dış turizmin tanıtımı konusundaki ekonomik ve sosyal faaliyetlere öncelik verilmesi, ulaşılmak istenen hedeflerin belirlenmesi, turizm sektörünün rekabet ortamında maruz kaldığı tehdit ve firsat unsurları gözlemlenerek gerekli düzenlemelerin yapılması, yeni stratejilerin uygulanması turizmin ülke ekonomisine katkısının uzun süreli olmasını sağlayacaktır.

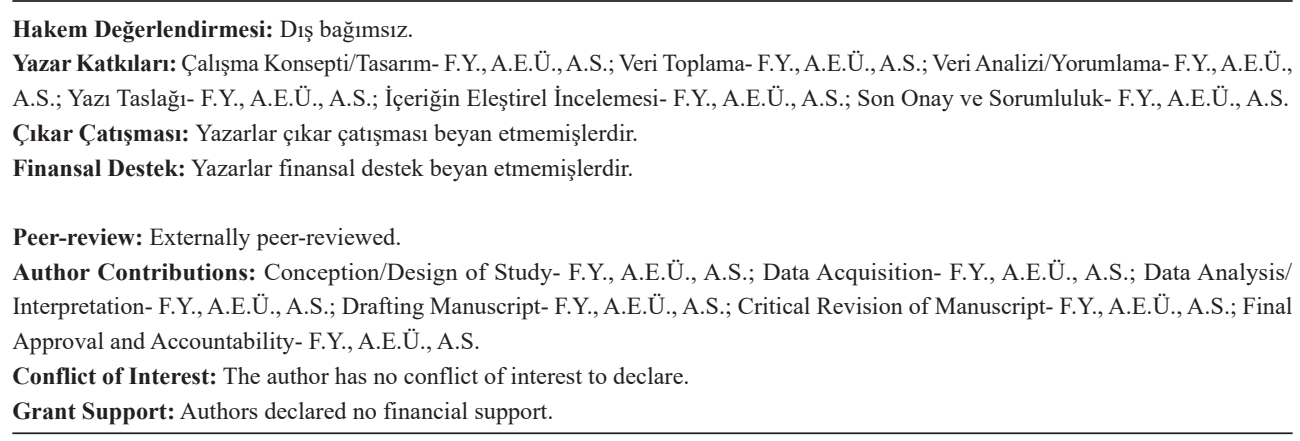

\section{Kaynakça/References}

A\&T Bank (2020), Turizm Sektörü Ekonomik Araştırmalar Departmanı, https:// www.atbank.com.tr/documents/ TURIZM\%20SEKTOR\%20RAPORU\%20\%20MAYIS\%202020.PDF (Erişim Tarihi:18.04.2021).

Aharon, D. Y. (2020). Sentiment, confidence and uncertainty: The case of tourism and leisure stocks. Cornell Hospitality Quarterly, 1938965520978170.

Arabacı, H. (2018). Turizm Sektörünün Ekonomik Büyümeye Etkisi Üzerine Teorik Bir İnceleme. Balkan ve Yakın Doğu Sosyal Bilimler Dergisi, 4(3), 104-109.

Arslantürk, Y. \& Atan, S. (2012). Dynamic Relation between economic growth, foreign exchange and tourism incomes: An econometric perspective on Turkey, Journal of Business, Economics and Finance, 1(1), 30-37. 
Ayaydın, H., Baltacı, N., Pala, F., \& Barut, A. (2019). Türkiye'de turizm, finansal gelişme ve ekonomik büyüme arasındaki ilişki. Global Journal Of Economics And Business Studies, 8(15), 69-84.

Bahar, O. (2006). Turizm sektörünün Türkiye'nin ekonomik büyüme üzerindeki etkisi: VAR analizi yaklaşımı, yönetim ve ekonomi, Celal Bayar Üniversitesi, İI. B.F. Dergisi, Manisa, 2(13), 137-138

Bahar, O., \& Bozkurt, K. (2010). Gelişmekte olan ülkelerde turizm-ekonomik büyüme ilişkisi: dinamik panel veri analizi. Anatolia: Turizm Araştırmaları Dergisi, 21(2), 255-265.

Balıkçığlu, E., \& Oktay, K. (2015). Türkiye'de turizm gelirleri ve ekonomik büyüme ilişkisinin kamu politikaları doğrultusunda değerlendirilmesi. Sosyoekonomi, 23(25), 113-126.

BDDK(2021). Aylık Bankacılık Sektör Verileri, Sektörel Kredi Dağılımı https://www.bddk.org.tr/BultenAylik (Erişim Tarihi: 18.04.2021).

Brida, J.G., Carrera, E. \& Risso, W.A. (2008). A long-run equilibrium demand function: The Mexican tourism, TOURISMOS: an International Multidisciplinary Journal of Tourism, Volume 3, Number 1, ss. 66-82.

Bozgeyik, Y., \& Yoloğlu, Y. (2015). Türkiye'de turizm gelirleri ile GSYH arasındaki ilişki: 2002-2014 dönemi. Journal of International Social Research, 8(40).

Caldara, D., \& Iacoviello, M. (2018). Measuring Geopolitical Risk. International Finance Discussion Papers, No:1222.

Chen, C. \& Chiou-Wei, S.Z. (2009). Tourism expansion, tourism uncertainty and economic growth: New evidence from Taiwan and Korea, Tourism Management, 30, ss.812-818.

Croce, V. (2016). Can tourism confidence index improve tourism demand forecasts?. Journal of Tourism Futures, 2(1), pp. 6-21.

Çımat, A. \& Bahar, O. (2003), Turizm sektörünün Türkiye ekonomisi içindeki yeri ve önemi üzerine bir değerlendirme, Akdeniz I.I.'B.F. Dergisi (6), 1-18.

Çınar, M., Yetkin, F., \& Bektaş, S. (2019). Elektrik tüketiminin sürdürülebilir kalkınmaya etkisi: Türkiye üzerine ampirik ve davranışsal bir inceleme, Uluslararası Işsletme Ekonomi ve Politika Dergisi, 3(2), 345-366.

Çoban, O. \& Özcan, C. (2013). Türkiye'de turizm gelirleri-ekonomik büyüme ilişkisi: Nedensellik analizi (19632010). Eskişehir Osmangazi Üniversitesi İIBF Dergisi, 8(1): 243-261.

De Vita, G., \& Kyaw, K. S. (2016). Tourism development and growth, çevrimiçi, https://repository.cardiffmet. ac.uk/handle/10369/9494, erişim tarihi: 20.02.2021.

Deloitte (2020). Türkiye'de turizm ve konaklama sektörü / COVID-19, https:// www2.deloitte.com/tr/tr/pages/ consumer-business/articles/turkiye-de-turizm-ve-konaklama-sektoru-covid-19.html (Erişim Tarihi:18.04.2021).

Dickey, D.A. \& Fuller, W.A. (1979). Distributions of the estimators for autoregressive time series with a unit root. Journal of the American Statistical Association, 74(366), pp.427-431.

Dickey, D.A. \& Fuller, W.A. (1981). Likelihood ration statistics for autoregressive time series with a unit root. Econometrica, 49(4), 1057-1072.

Eyüboğlu, S., \& Eyüboğlu, K. (2018). Hizmet Güven Endeksi İle Hizmet Sektör Alt Endeksleri Arasındaki İlişkisinin Test Edilmesi. Afyon Kocatepe Üniversitesi Sosyal Bilimler Dergisi, 20(2), 271-282.

Fareed, Z., Meo, M. S., Zulfiqar, B., Shahzad, F., \& Wang, N. (2018). Nexus of tourism, terrorism, and economic growth in Thailand: new evidence from asymmetric ARDL cointegration approach. Asia Pacific Journal of Tourism Research, 23(12), 1129-1141.

Fayed, H. \& Fletcher, J. (2002). Globalization of Economic Activity: Issues for Tourism, Tourism Economics, 8 (2), 207-230.

Gholipour, H. F., Nunkoo, R., Foroughi, B., \& Daronkola, H. K. (2021). Economic policy uncertainty, consumer 
confidence in major economies and outbound tourism to African countries. Tourism Economics, 1354816620985382.

Granger, C.W.J. (1969). Investigating causal relations by econometric models and crossspectral methods, Econometrica, 37(3), 424-438.

Gündüz, L. \& Abdulnasser H. (2005). Is the tourism-led growth hypothesis valid for Turkey, Applied Economics Letters, 12(8), 499-504.

İçöz, O. \& Kozak, M. (1998). Turizm Ekonomisi, 1. Bask1, Turhan Kitabevi, Ankara.

İskenderoğlu, Ö. \& Akdağ, S. (2017). Finansal hizmetler güven endeksinin geçerliliğinin incelenmesi: Türkiye örneği, Uluslararası Ekonomik Araştırmalar Dergisi, 3(4): 625-633.

Kandemir, T., Arifoğlu, A., \& Canbaz, M. F. (2018). Sektörel krediler ve ekonomik büyüme arasındaki nedensellik ilişkisi: Türkiye katılım bankaları örneği. Aksaray Üniversitesi İktisadi ve İdari Bilimler Fakültesi Dergisi, 10(2), 19-30.

Kandır, Y. S., E. Karadeniz, M. Özmen, \& Y. B. Önal. (2008). Türk turizm sektöründe büyüme göstergelerinin turizm işletmelerinin finansal performansına etkisinin incelenmesi, Dokuz Eylül Üniversitesi Sosyal Bilimler Enstitüsü Dergisi, 1(10), 211-237.

Karadeniz, E. 2012. İstanbul Menkul Kıymetler Borsasında işlem gören turizm şirketlerinin işletme, finansal ve toplam risk düzeylerinin kaldıraç analiziyle değerlendirilmesi, Süleyman Demirel Üniversitesi İktisadi ve İdari Bilimler Fakültesi Dergisi, 1(17), 309-324.

KGF (2021), Turizm Destek Paketi, https:// www.kgf.com.tr/ index.php/tr/urunlerimiz/hazine-destekli-kefaletler/ turizm-destek-paketi. (Erişim Tarihi:18.04.2021).

Kwiatkowski, D., Phillips, P.C. B., Schmidt, P. \& Shin, Y. (1992). Testing the null hypothesis of stationarity against the alternative of a unit root: How sure are we that the economic time series have a unit root? Journal of Econometrics, 54, 159-178.

Ohlan, R. (2017). The relationship between tourism, financial development and economic growth in India. Future Business Journal, 3(1), 9-22.

Pata, U. K. (2020). Turizm, finansal gelişme, ticari açıklık ve sermaye stokunun ekonomik büyüme üzerindeki etkileri: Türkiye örneği. Çukurova Üniversitesi Sosyal Bilimler Enstitüsü Dergisi, 29(4): 151-167.

Samimi, A., Sadeghi, S.\& Sadeghi, S. (2011). Tourism and economic growth in developing countries: P-VAR approach. Middle-East Journal of Scientific Research, 10(1): 28-32.

Theobald, W. F. (2001). Global Tourism, Oxford: Butterworth\&Heinemann, Second Edition.

Toda, H. Y.,Yamamoto, T. (1995). Statistical inference in vector autoregressions with possbly integrated process. Journal of Econometrics, 66, pp 225-250.

Turgut, K. (2019). Banka Kredi Hacmi ile İktisadi Büyüme Arasındaki İlişki: Türkiye Örneği, Hacettepe Üniversitesi Sosyal Bilimler Enstitüsü İktisat Anabilim Dalı, Yüksek Lisans Tezi, Ankara.

TÜRSAB (2021), Turizm Rapor ve İstatistikleri, Turizm Gelirleri, https: // www.t ursab.org.tr/ turizm-geliri / turizm-gelirleri (Erişim Tarihi: 18.04.2021).

Uğurlu, S. (2020), Türkiye’de Bankacılık Sektörü Kredilerinin Dış Ticaret Üzerindeki Etkisi, Uluslararası Ticaret ve Finans, Ekin, Ankara .113-128.

Ünlüönen, K. \& Şahin, S. Z. (2011). Turizmde İstihdam, Elektronik Sosyal Bilimler Dergisi 10(37), 1-25.

Yılmaz, H. (2007). Turizm sektörü kobilerinin finansman sorunlarının diğer sektörlerle karşılaştırmalı analizi: Bodrum örneği. Muhasebe ve Finansman Dergisi, (33), 162-170. 